\title{
American Society of Regional Anesthesia and Pain Medicine Local Anesthetic Systemic Toxicity checklist: 2020 version
}

\author{
Joseph M Neal ㄷ, , Erin J Neal, ${ }^{2}$ Guy L Weinberg ${ }^{3,4}$
}

${ }^{1}$ Benaroya Research Institute at Virginia Mason Medical Center, Seattle, Washington, USA ${ }^{2}$ Laguna College of Art+Design, Laguna Beach, California, USA ${ }^{3}$ Anesthesiology, University of Illinois at Chicago, Chicago, Illinois, USA

${ }^{4}$ Anesthesiology, Jesse Brown VA Medical Center, Chicago, Illinois, USA

Correspondence to Dr Joseph M Neal, Anesthesiology, Virginia Mason Medical Center, Seattle, WA 98111-0900, USA; joeneal@comcast.net

Received 1 August 2020 Revised 12 October 2020 Accepted 13 October 2020 Published Online First 4 November 2020

\section{ABSTRACT}

The American Society of Regional Anesthesia and Pain Medicine (ASRA) periodically updates its practice advisories and associated cognitive aids. The 2020 version of the ASRA Local Anesthetic Systemic Toxicity checklist was created in response to user feedback, simulation studies and advances in medical knowledge. This report presents the 2020 version and discusses the rationale for its update.

\section{INTRODUCTION}

The American Society of Regional Anesthesia and Pain Medicine (ASRA) periodically updates its practice advisory on Local Anesthetic Systemic Toxicity (LAST) ${ }^{12}$ to incorporate knowledge advancement, feedback sourced from users ${ }^{3}$ and simulation. ${ }^{45}$ Coincident with these ongoing advances, ASRA LAST management checklists $^{167}$ and ASRA LAST smartphone applications are often revised. Herein, we present the 2020 version of the ASRA LAST checklist (figure 1) and discuss the rationale for its redesign.

\section{DISCUSSION}

Design of the 2020 checklist was strongly impacted by a simulation study that identified latent design deficiencies in the 2017 version. $^{8}$ Similarly, the original 2010 LAST checklist was modified in $2012^{6}$ based on a simulation study ${ }^{5}$ that assessed its effectiveness and readability, and it then underwent further modification embodied in the 2017 practice advisory. ${ }^{2}$ The 2017 update involved experts in checklist design ${ }^{7}$ and specifically intended to address ambiguities ${ }^{3}$ and misunderstandings related to lipid emulsion dosing, resuscitation drug selection and timely notification of cardiopulmonary bypass teams. However, a simulation study published in Regional Anesthesia and Pain Medicine compared the 2017 LAST checklist with the 2012 version that it replaced and found no difference in effectiveness or readability. ${ }^{4}$

The 2020 checklist's most important modification was conversion of the traditional bullet-pointed design to a process-flow format similar to the ASRA LAST smartphone application. ${ }^{9}$ This change responds to some simulation participants who found portions of

\section{Linked}

- http://dx.doi.org/10.1136/ rapm-2020-101870

Check for updates

(C) American Society of Regional Anesthesia \& Pain Medicine 2021. No commercial re-use. See rights and permissions. Published by BMJ.

To cite: Neal JM, Neal EJ, Weinberg GL. Reg Anesth Pain Med 2021:46:81-82.

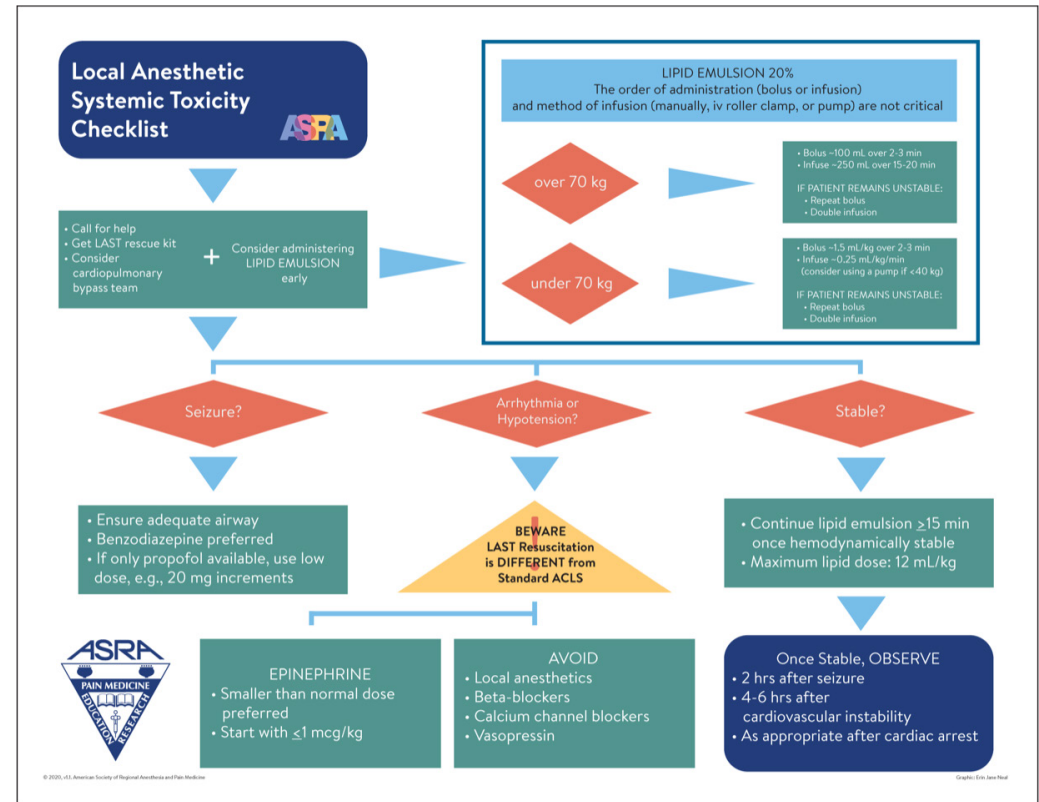

Figure 1 Copyright 2020 by the American Society of Regional Anesthesia and Pain Medicine, which hereby grants practitioners the right to reproduce the checklist graphic as part of a clinical system for managing LAST. Formats suitable for reproduction and lamination can be obtained at www.asra.com free of charge.Scholarly publication of these recommendations should be cited as: Neal et al Publication or reproduction of the checklist for commercial use requires written permission from ASRA. Graphic: Erin J. Neal. ACLS, Advanced Cardiac Life Support; LAST, Local Anesthetic Systemic Toxicity. 
both the 2012 and 2017 checklists difficult to follow and wordy. For instance, the 2012 checklist prescribes airway management during seizure as 'ventilate with 100\% oxygen' while the 2017 checklist task prescribes 'ventilate with 100\% oxygen/avoid hyperventilation/ advanced airway device if necessary'. Indeed, subjects that were randomized to the less wordy 2012 checklist performed slightly better on LAST management tasks (a secondary outcome, effect size $1.01),{ }^{4}$ which in part supports using a more concise format. Therefore, instead of using a sequential list of management steps, we aim to improve critical incident management with a process-flow format that identifies individual decision points such as seizure management (standard diamond shape) and links treatment to specific actions (process rectangles). ${ }^{10}$

Simulation and user feedback also highlighted an important and ongoing management deficit-failure to recognize that LAST resuscitation differs from Advanced Cardiac Life Support (ACLS)-guided resuscitation (animal studies show that many standard ACLS drugs worsen LAST outcomes). ${ }^{11}$ When some simulation subjects chose to use both LAST and ACLS checklists, the resulting confusion and missteps led to delayed and errant treatment. ${ }^{4}$ Admonitions placed near the top of previous checklists did not eliminate this defect, thus the 2020 redesign incorporates a standard triangular caution symbol to emphasize therapeutic differences. We further simplified lipid emulsion dosing instructions in response to reported difficulties calculating weight-based dosing and timing of lipid administration, ${ }^{3}$ which reflect practitioner preference for a level of precision that is unnecessary and unsupported by experimental studies.

In summary, the 2020 version of the ASRA LAST checklist was created in response to advances in medical knowledge, user feedback and simulation. We hope that a process-flow format achieves a more concise and logical cognitive aid.

Correction notice This article has been corrected since it published Online First. Figure 1 has been replaced.

Twitter Guy L Weinberg @lipidguy

Contributors JMN contributed to checklist content and prepared and approved the manuscript. EJN rendered graphic design and approved the manuscript. GLW contributed to checklist content and prepared and approved the manuscript.
Funding The authors have not declared a specific grant for this research from any funding agency in the public, commercial or not-for-profit sectors.

Competing interests JMN and GLW served on the 2010 and 2017 American Society of Regional Anesthesia and Pain Medicine (ASRA). Local Anesthetic Systemic Toxicity practice advisory panels. GLW is an officer and shareholder of ResQ Pharma. EJN was compensated for graphic design.ASRA approved the 2020 version of this checklist, but had no input into its scientific content.

Patient consent for publication Not required.

Provenance and peer review Not commissioned; externally peer reviewed. Data availability statement There are no data in this work.

ORCID iD

Joseph M Neal http://orcid.org/0000-0001-9754-7077

\section{REFERENCES}

1 Neal JM, Bernards CM, Butterworth JF, et al. ASRA practice Advisory on local anesthetic systemic toxicity. Reg Anesth Pain Med 2010;35:152-61.

2 Neal JM, Barrington MJ, Fettiplace MR, et al. The third American Society of regional anesthesia and pain medicine practice Advisory on local anesthetic systemic toxicity: Executive summary 2017. Reg Anesth Pain Med 2018;43:113-23.

3 Thompson BM. Revising the 2012 American Society of regional anesthesia and pain medicine checklist for local anesthetic systemic toxicity: a call to resolve ambiguity in clinical implementation. Reg Anesth Pain Med 2016:41:117-8.

4 Hsiung RL, Bean HA, Stafford CE, et al. Simulation study comparing readability and effectiveness of the 2012 versus 2017 ASRA local anesthetic systemic toxicity checklists. Reg Anesth Pain Med. 2020:1-3.

5 Neal JM, Hsiung RL, Mulroy MF, et al. ASRA checklist improves trainee performance during a simulated episode of local anesthetic systemic toxicity. Reg Anesth Pain Med 2012:37:8-15.

6 Neal JM, Mulroy MF, Weinberg GL, et al. American Society of regional anesthesia and pain medicine checklist for managing local anesthetic systemic toxicity: 2012 version. Reg Anesth Pain Med 2012;37:16-18.

7 Neal JM, Woodward CM, Harrison TK. The American Society of regional anesthesia and pain medicine checklist for managing local anesthetic systemic toxicity: 2017 version. Reg Anesth Pain Med 2018;43:150-3.

8 Park CS. Simulation and quality improvement in anesthesiology. Anesthesio/ Clin 2011;29:13-28.

9 Gupta RK, McEvoy MD. Initial experience of the American Society of regional anesthesia and pain medicine Coags regional smartphone application: a novel report of global distribution and clinical usage of an electronic decision support tool to enhance guideline use. Reg Anesth Pain Med 2016;41:334-8.

10 Wikipedia. Flowchart common symbols. Available: https://en.wikipedia.org/wiki/ Flowchart [Accessed $28 \mathrm{Jul}$ 2020].

11 Fettiplace MR, Weinberg G. The mechanisms underlying lipid resuscitation therapy. Reg Anesth Pain Med 2018:43:138-49. 